\title{
HOLMIUM LASER SCLEROSTOMY: A CLINICAL STUDY
}

\author{
J. A. McALLISTER and P. O. WATTS \\ Windsor
}

\begin{abstract}
SUMMARY
A prospective study of 30 glaucoma patients (one eye in each patient) treated by an ab externo holmium laser sclerostomy is presented. An average of $\mathbf{4 0 . 2}$ pulses with an energy of $100 \mathrm{~mJ}$ was necessary to produce a filtering bleb. The average pre-operative intraocular pressure was $25.5 \pm 7.4 \mathrm{mmHg}$, with an average of $14.06 \pm 5.7 \mathrm{mmHg}$ post-operatively at the final follow-up. The mean follow-up was 7.5 months (range 5-12 months) and the mean age of the patients was 71.4 years. Using strict criteria $70 \%$ of sclerostomies were considered successful at the final follow-up visit. The main post-operative complication was iris plugging of the sclerostomy. This was dealt with successfully with a ' $Q$ '-switched neodymium:YAG laser in $80 \%$ of cases. Our early experience with the laser suggests that it is an easy, quick method of producing a filtering bleb, and may be carried out as an office procedure. As the technique evolves its long-term success remains to be evaluated; however, it shows promise both as an alternative to trabeculectomy as a primary procedure and as an additional technique for more complicated cases of glaucoma.
\end{abstract}

The THC:YAG laser is a solid state infrared laser with a wavelength of $2100 \mathrm{~nm}$. Thulium and chromium are used as sensitisers which improve the efficiency of the laser, holmium is the active element and the solid crystal doped is yttrium aluminium garnet (YAG). The laser energy is delivered at the end of a 22 gauge $(712 \mu \mathrm{m})$ probe, at $90^{\circ}$ to the long axis of the probe. A helium-neon ( $\mathrm{HeNe}$ ) aiming beam is used for orientation. The mechanism of production of a sclerostomy is by the interaction of the infrared laser radiation and water absorption of the corneoscleral tissue. The procedure involves less conjunctival manipulation and consequently less post-operative inflammation and scarring compared with conventional filtering procedures.

We present our early experience with the use of this laser, the complications encountered and their management.

Correspondence to: J. A. McAllister, Prince Charles Eye Unit, King Edward VII Hospital, Windsor SL4 3QQ, UK.

\section{MATERIALS AND METHODS}

Patients who were scheduled to undergo glaucoma filtering surgery were offered enrolment in the study. The inclusion criteria were failure of maximally tolerated medical therapy with or without previous argon laser trabeculoplasty, an intraocular pressure (IOP) considered unsafe for the degree of optic nerve head damage present, and progressive field loss despite adequate IOP control. Thirty patients underwent the procedure in one eye. Twenty-five patients had primary open angle glaucoma (POAG), 2 had secondary glaucoma after penetrating corneal grafts, 2 had normal pressure glaucoma (NPG) and 1 had chronic angle closure glaucoma (CACG); $26.7 \%$ were pseudophakic and $16 \%$ of them had previously failed trabeculectomies.

The mean age of the patients was 71.4 years (range 55-84 years). There were 14 men and 16 women. Twentyeight patients were Caucasian, 1 was Afro-Caribbean and 1 was Asian.

The pre-operative assessment included visual acuity, IOP (mean of three readings), gonioscopy disc assessment and threshold perimetry using an Octopus programme 34 or the Henson's Field Analyser.

\section{Procedure}

All operations were performed by one surgeon (J.A.M.). Topical amethocaine was instilled into the conjunctival $\mathrm{sac}$, and a $3 \mathrm{ml}$ mixture of $2 \%$ xylocaine and bupivicaine injected into the retrobulbar space. The patient's eye was cleaned and draped. With the use of an operating microscope a $1 \mathrm{~mm}$ conjunctival incision was made $12 \mathrm{~mm}$ away from the limbus, preferably in an area of virgin conjunctiva. The probe was calibrated to emit $100 \mathrm{~mJ}$ of energy per pulse at 5 pulses per second. The probe was then tunnelled through the conjunctival incision to reach the very limit of the conjunctival insertion at the limbus, and held tangentially so that the $\mathrm{HeNe}$ aiming beam pointed towards the centre of the anterior chamber. Laser emission was initiated by pressing a foot pedal. Entry into the anterior chamber was heralded by (1) a change in tone of the laser emission from a dull thumping sound to a 


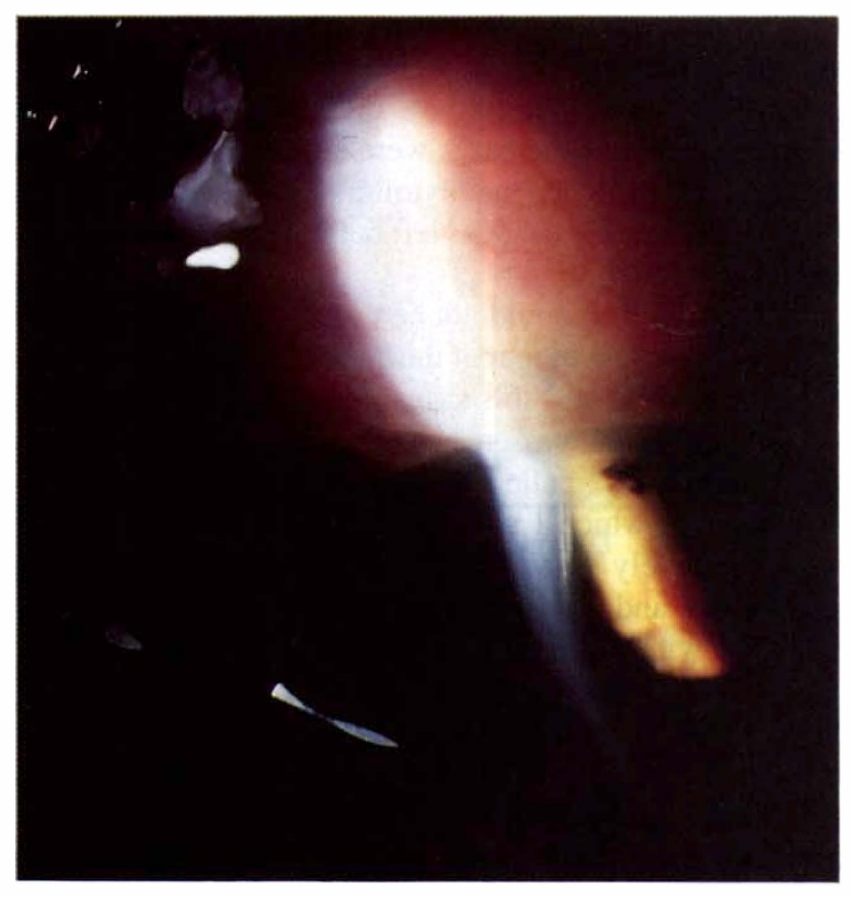

(a)

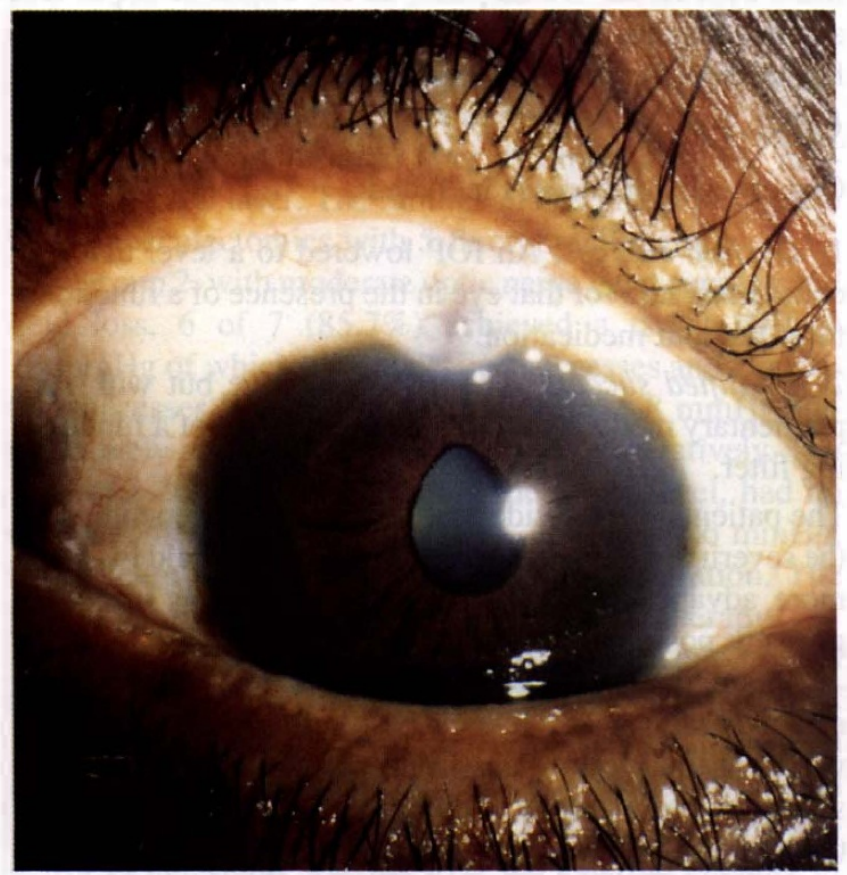

(c)

sharp cracking sound, (2) the presence of small bubbles in the anterior chamber, (3) the release of pigment into the anterior chamber, (4) the movement of the iris and its peaking when the probe was elevated and (5) the formation of a large bleb when the probe was withdrawn. The laser was fired again after allowing the iris to prolapse into the sclerostomy, in effect creating an iridotomy. A 10-0 nylon suture was used to close the conjunctival incision. A scleral contact lens was inserted at the end of the procedure.

The average number of pulses needed to complete the

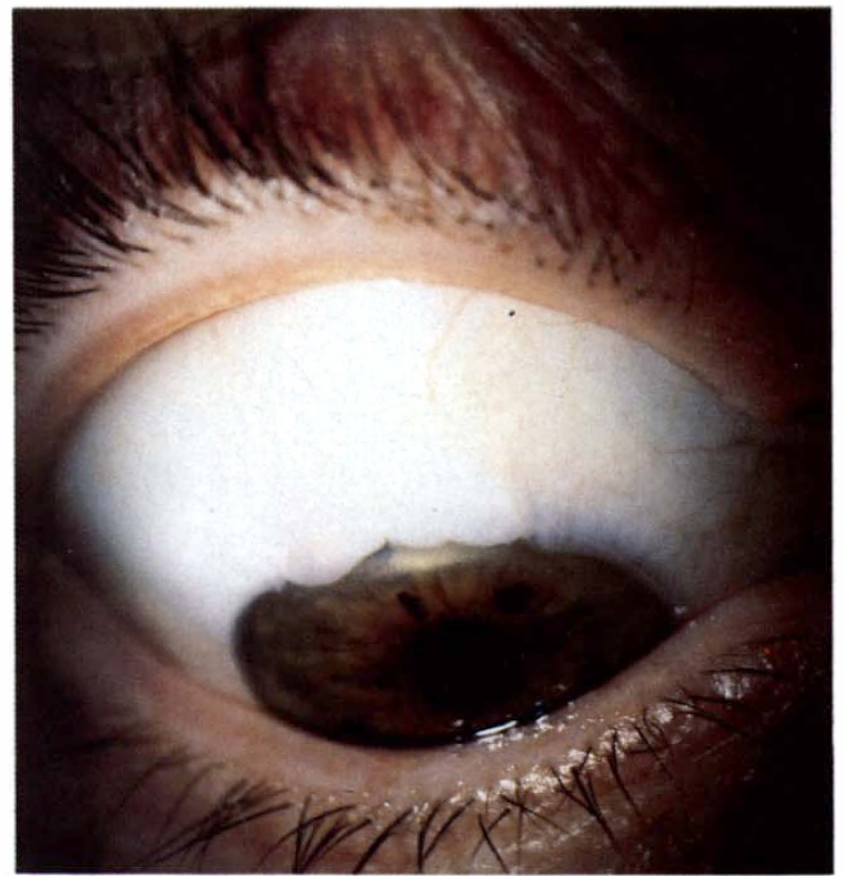

(b)

Fig. 1. (a) Large and diffuse filtering bleb first day postoperatively. (b) Shallow diffuse bleb with small cysts at the limbus in the same patient, 12 months later. (c) Localised cystic bleb in another patient 12 months post-operatively.

procedure was 40.2 (range 17-99). The average total energy was 4.1 joules (range of 1.7-11.2 joules).

The scleral contact lens was removed on the first postoperative day if the anterior chamber was well formed and the IOP above $5 \mathrm{mmHg}$. None of the eyes required the scleral contact lens for more than 48 hours. Post-operatively the eye had a large diffuse bleb, with corneal striae radiating from the site of the sclerostomy; the anterior chamber was about half chamber depth with evidence of stromal iris atrophy and in $50 \%$ of cases a full-thickness iridotomy. 


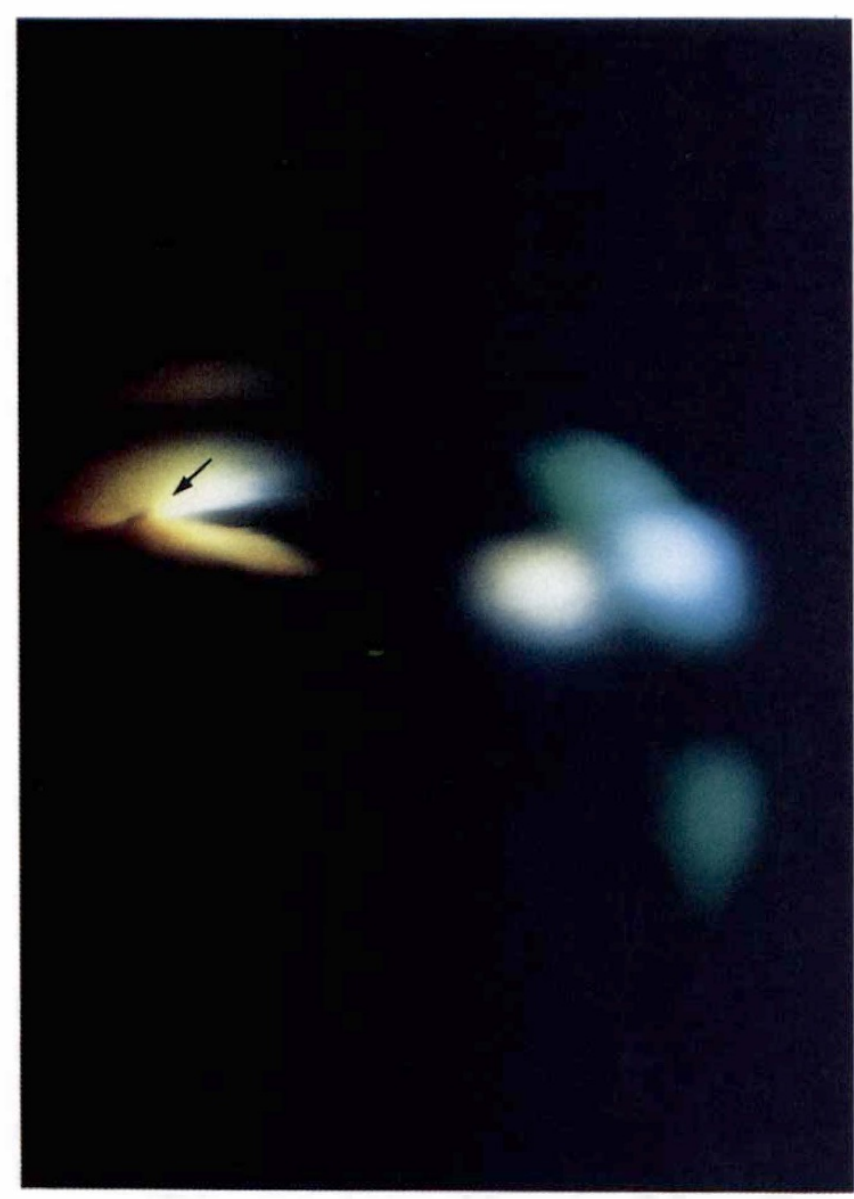

Fig. 2. Gonioscopic picture illustrating an iris plug (arrow) of the internal sclerostomy opening.

The early post-operative blebs were large (Fig. 1a), but settled down to a shallow diffuse bleb with a few cystic spaces by 12 months post-operatively (Fig. 1b); however, a few patients had a localised cystic bleb (Fig. 1c) 12 months post-operatively. There was no particular character to a bleb produced by holmium laser and many resembled blebs produced by conventional trabeculectomies.

Follow-up visits were carried out on the first postoperative day and then every week for a month and every month for 6 months. Visual acuity was tested, IOP measured and gonioscopy performed at every post-operative visit to exclude the presence of iris plugging of the sclerostomy. Follow-up ranged from 5 to 12 months.

\section{RESULTS}

\section{Complications}

The main post-operative complication $(46 \%)$ was iris

Table I. Desired successes in groups 1, 2 and 3 incarceration of the sclerostomy (Fig. 2). The majority occurred within the first week post-operatively, but 1 patient had iris plugging 4 months post-operatively. Eighty per cent of the cases were successfully dealt with using a 'Q'-switched neodymium:YAG laser. It is not known whether iris tissue is left behind in the sclerostomy after this treatment.

A filtration bleb could not be produced in 1 patient due to formation of an eschar at the site of proposed entry into the anterior chamber; this case went on to trabeculectomy.

Hyphaema was present in 3 patients, subconjunctival haemorrhage in 2 patients, and conjunctival buttonholes in 3 cases, of which 1 was recognised as an aqueous leak post-operatively (the latter sealed spontaneously). The hyphaemas and the subconjunctival haemorrhages disappeared within the first post-operative week. The conjunctival buttonholes recognised during surgery were closed with 10-0 nylon and another site chosen for the sclerostomy.

One patient had a transient rise in IOP on the first postoperative day which was resolved with massage of the bleb. All the eyes that had a filtering bleb on the first postoperative day had a shallow anterior chamber; none of these eyes required treatment, as full chamber depth was achieved by the first week post-operatively. No eyes had flat anterior chambers in our study.

\section{Success Rates}

Our criteria for success included:

1. Desired success: An IOP lowered to a level that was considered safe for that eye in the presence of a functional filter without medication.

2. Qualified success: The same as above but with supplementary medical therapy in the presence of a functioning filter.

The patients were divided into three groups depending on the severity of optic nerve head cupping and field loss. The more advanced the glaucoma, the lower was the target pressure post-operatively.

On the first post-operative day all patients in all groups achieved their target IOPs. The results presented are the values at final follow-up. The mean IOP of the qualified successes before medical therapy was added has not contributed to the value of our data, as the medical therapy was started at different times as and when the IOP went above the target pressure for a patient in that particular group.

In group 1, with advanced optic nerve head cupping and

\begin{tabular}{ccccc}
\hline Group & $\begin{array}{c}\text { Desired success }^{\mathrm{a}} \\
\text { (total no. of patients) }\end{array}$ & $\begin{array}{c}\text { Pre-operative IOP (mmHg) with } \\
\text { maximally tolerated medication }\end{array}$ & $\begin{array}{c}\text { Post-operative IOP (mmHg) at final } \\
\text { follow-up visit without medication } \\
(5-12 \text { months) }\end{array}$ & $\begin{array}{c}\% \text { achieving target } \\
\text { IOP (target IOP in each group) }\end{array}$ \\
\hline 1 & $10(18)$ & $23.3 \pm 5.3$ & $9.0 \pm 2.5$ & $55.6(12 \mathrm{mmHg})$ \\
2 & $4(7)$ & $29.8 \pm 5.7$ & $11.5 \pm 3$ & $60.0(16 \mathrm{mmHg})$ \\
3 & $3(5)$ & $25.3 \pm 2.1$ & $17.0 \pm 6.1$ & $57.0(18 \mathrm{mmHg})$ \\
\hline
\end{tabular}

${ }^{a}$ Desired successes were those who achieved a target pressure of $12 \mathrm{mmHg}$ or lower in group $1,16 \mathrm{mmHg}$ or lower in group 2 , and $18 \mathrm{mmHg}$ or less in group 3, without supplementary medical therapy, with a functioning bleb. 


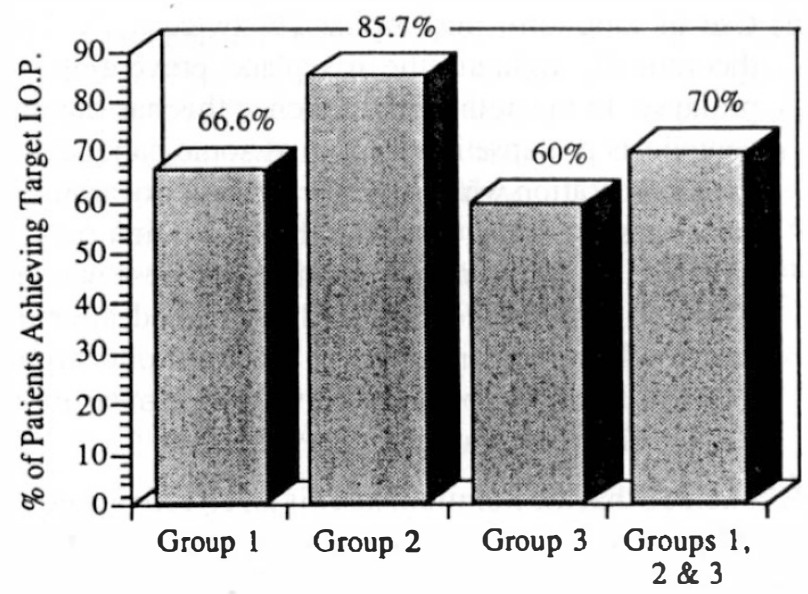

Fig. 3. Percentage of patients achieving target IOP. Group 1 , target IOP $12 \mathrm{mmHg}$; group 2, target IOP $16 \mathrm{mmHg}$; group 3, target IOP $18 \mathrm{mmHg}$.

extensive field loss, 12 of $18(66.6 \%)$ came within a target IOP of $12 \mathrm{mmHg}$ (Fig. 3), of which 10 were desired successes (Table I) and 2 were qualified successes. The mean IOP was $24.5 \pm 8.2 \mathrm{mmHg}$ pre-operatively and $13.1 \pm 5.8 \mathrm{mmHg}$ post-operatively at the final follow-up (Fig. 4). Two failed because of gradual shrinkage of the size of the bleb, probably a result of the sclerostomy opening being too small. The remaining 4 failures in this group were due to iris incarceration of the sclerostomy which could not resume filtration after treatment with the neodymium:YAG laser. The failures in this group went on to have trabeculectomies with 5-fluorouracil therapy.

In group 2, with moderate optic nerve head cupping and field loss, 6 of $7(85.7 \%)$ achieved a target IOP of $16 \mathrm{mmHg}$ of which 4 were desired successes and 2 qualified successes. The mean IOP was $26.2 \pm 6.8 \mathrm{mmHg}$ preoperatively and $12.8 \pm 4.0 \mathrm{mmHg}$ post-operatively. The 1 failure, despite an IOP within the target level, had no obvious bleb. The pre-operative IOP was $26 \mathrm{mmHg}$, hence there must have been some occult filtration. The patient continues to be on maximal medical therapy.

In group 3, with early optic nerve head cupping and field loss, 3 of $5(60 \%)$ achieved the target IOP of $18 \mathrm{mmHg}$, all of which were desired successes. The mean IOP was $28.0 \pm 5.3 \mathrm{mmHg}$ pre-operatively and $18 \pm 5.9 \mathrm{mmHg}$ post-operatively. The 2 failures had evidence of episcleral scarring over the external opening of the sclerostomy when a trabeculectomy was done.

The mean number of medications used pre-operatively was $2.2 \pm 0.7$; the mean number of medications used post-operatively (as calculated at the final post-operative visit) was $0.8 \pm 1.0$. Each topical medication was equivalent to a score of 1 point, and diamox was equivalent to a score of 1 point. The details are presented in Table II.

The overall success rate with one holmium procedure was $70 \%$. There was no deterioration of vision in any patient. If the criteria for success used in other studies are followed (i.e. IOP $<21 \mathrm{mmHg}$ ) the success rate of our study is $83.3 \%$.

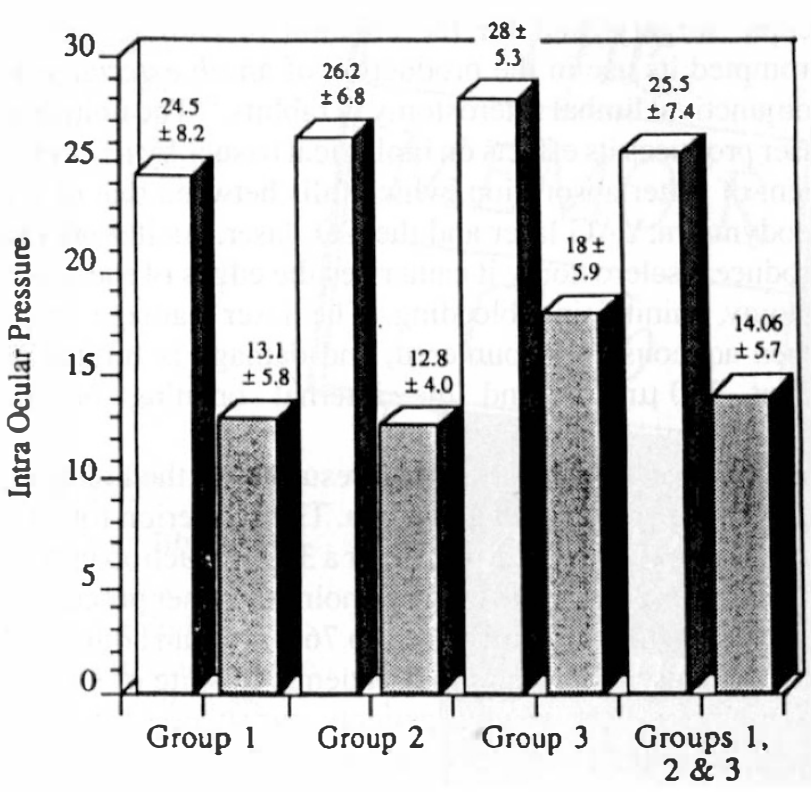

Fig. 4. Mean pre-operative IOP (open columns) and mean post-operative IOP at final follow-up (shaded columns). Group 1 , advanced optic nerve head cupping and extensive field loss $(n=18)$; group 2, moderate optic nerve head cupping and field loss $(n=7)$; group 3, early optic nerve head cupping and field loss $(n=5)$.

Of the 30 patients, $17(56.7 \%)$ were desired successes who achieved their target pressures without supplementary medical therapy. In these 17 patients the mean IOP pre-operatively with maximally tolerated medical therapy was $25.5 \pm 5.5 \mathrm{mmHg}$ and the mean post-operative IOP without supplementary medical therapy was $11.6 \pm 4.4 \mathrm{mmHg}$. The mean post-operative IOP in our study was calculated at 4-6 months after surgery depending on the length of follow-up.

\section{DISCUSSION}

Since the introduction of trabeculopuncture by Krasnov in 1973 with the use of the ruby laser, ${ }^{1}$ the neodymium:YAG laser and the argon laser have been used to lower the IOP. However, the effectiveness of these procedures (trabeculopuncture and trabeculoplasty) decreases with time, so that after 5 years only $30-60 \%$ of the cases treated with these modalities maintain a satisfactory IOP. ${ }^{2-4}$

Filtering blebs have been produced experimentally with the neodymium:YAG laser, ${ }^{5}$ the $\mathrm{CO}_{2}$ laser $^{6}$ and the excimer laser. ${ }^{7}$ The use of the holmium laser in endo-

Table II. Mean number of pre- and post-operative medications

\begin{tabular}{lcc}
\hline & Pre-operative & Post-operative \\
\hline Group 1 & $2.2 \pm 0.9$ & $0.5 \pm 0.9$ \\
Group 2 & $2 \pm 0.5$ & 0 \\
Group 3 & $2.2 \pm 0.4$ & $1.6 \pm 1.1$ \\
Groups 1, 2 and 3 & $2.2 \pm 0.7$ & $0.8 \pm 1.0$ \\
\hline
\end{tabular}

Each topical medication and oral diamox was equivalent to 1 point. The maximum medication tolerated by any patient was equivalent to 4 points. 
scopic surgery ${ }^{8}$ and for the ablation of cardiac valves ${ }^{9}$ prompted its use in the production of an ab externo subconjunctival limbal sclerostomy in rabbits. ${ }^{10}$ The holmium laser produces its effects on biological tissues by its coefficient of water absorption, which falls between that of the neodymium:YAG laser and the $\mathrm{CO}_{2}$ laser. As it works to produce a sclerostomy it cauterises the edges of the sclerostomy, minimising bleeding. The laser damage stops when aqueous is encountered, and damage is limited to about $300 \mu \mathrm{m}$ around the internal opening of the sclerostomy.

Hoskins et al. ${ }^{11}$ reported their results with the holmium laser in 21 patients with glaucoma. Their criterion for success was an IOP of $<22 \mathrm{mmHg}$ or a $30 \%$ reduction in IOP. The overall success rate with one holmium laser procedure was $57 \%$, which was increased to $76 \%$ with an additional holmium laser procedure in 5 patients. In spite of stricter criteria for a success in our patients, our success rate for a single holmium laser procedure was $70 \%$.

As experience with the use of the laser grew, techniques were introduced to prevent the major complication of iris incarceration of the sclerostomy. These include:

1. Pre-operative measures

(i) Use of pilocarpine drops.

(ii) Argon laser iridoplasty to stiffen the iris, preventing its prolapse. This was performed in 1 patient, who has no iris incarceration 6 months post-operatively. About $200 \mu \mathrm{m}$ with an energy of $300 \mathrm{~mW}$ was used to treat the superior iris below the proposed site of the sclerostomy.

2. Operative measures

(i) Operative iridotomy, as discussed under Procedure above.

(ii) The use of healon both to prevent and to treat iris incarceration of the sclerostomy has been described. This manoeuvre was not used in our study.

(iii) As the first sclerostomy is completed the probe is pushed onto a new site on the limbus adjacent to the first and another sclerostomy is made. The theory behind this technique is that it may be harder for the iris to incarcerate two sclerostomies in close proximity.

3. Post-operative measures

(i) Use of a filtration control lens (developed by the author J.A.M.). This is a large-diameter soft contact lens, which has sufficient peripheral rigidity to prevent excessive filtration. The lens may be left in situ for 48-72 hours without any corneal problems; it is removed on the first post-operative day if the anterior chamber is well formed. None of the eyes required the use of the contact lens for longer than 48 hours.

(ii) Gonioscopic examination at every post-operative visit even if the IOP is low (at least $>5 \mathrm{mmHg}$ ) and early use of the ' $Q$ '-switched neodymium:YAG laser when an iris plug is recognised. About 20 shots of $2-4$ pulses with an energy of $3-4 \mathrm{~mJ}$ is required to unblock the iris incarceration and treat an overhanging Descemet's flap. (iii) Use of long-term pilocarpine $2 \%$ twice daily. This theoretically tightens the iris plane preventing iris prolapse. In the authors' experience this has not prevented iris prolapse in all cases as some patients had iris incarceration while on pilocarpine. Pilocarpine in our series was only used initially in the first 6 eyes; however, iris plugging was seen in 3 of these patients while on pilocarpine. It was discontinued after the first week post-operatively. In 24 eyes pilocarpine was not instituted post-operatively as a measure to reduce iris incarcerations.

We conclude that the holmium laser is an effective method of producing a filtering sclerostomy; however, a longer follow-up is required to prove its superiority over or equality with other standard filtering procedures. It is easier to perform than other techniques and may be completed as an office procedure.

Conjunctival handling is reduced to a minimum. There is no anterior chamber manipulation with this procedure and problems with a post-operative flat anterior chamber have not been encountered. A power of $100-120 \mathrm{~mJ}$ is sufficient to create a sclerostomy of a size necessary for long-term filtration (150-200 $\mu \mathrm{m})$. However, the ideal size of the sclerostomy has yet to be worked out. This study is continuing and pathological investigations of the specimens from the failed cases that underwent trabeculectomies should yield information on the size of the sclerostomies that closed spontaneously.

Key words: Ab externo, Holmium laser, Sclerostomy.

\section{REFERENCES}

1. Krasnov MM. Laseropuncture of anterior chamber angle in glaucoma. Am J Ophthalmol 1973;75:674-8.

2. Sherwood MB, Lattimer J, Hitchings RA. Laser trabeculoplasty as supplementary treatment for primary open angle glaucoma. Br J Ophthalmol 1987;71:188-91.

3. Shingleton BF, et al. Long term efficacy of argon laser trabeculoplasty. Ophthalmology 1987;94:1513-7.

4. Wise JB. Long-term control of adult open angle glaucoma by argon laser trabeculoplasty. Ophthalmology 1981;13:49.

5. Gherezghiher NP, March WF, Koss MD, Nordquist RE. Neodymium:YAG laser sclerostomy in primates. Arch Ophthalmol 1985;103:1543-5.

6. Beckman H, Fuller TA. Carbon dioxide laser scleral dissection and filtering procedure for glaucoma. Am J Ophthalmol 1979;88:73-9.

7. Gaasterland DE, Hennings DR, Boutacoff TA, Bilek C. $A b$ interno and ab externo filtering operations by laser contact surgery. Ophthalmic Surg 1987;18:254-7.

8. Treat MR, et al. Preliminary evaluation of a pulsed $2.15 \mu \mathrm{m}$ laser system for fiberoptic endoscopic surgery. Lasers Surg Med 1988;8:322-6.

9. Lilge L, Radtke W, Nishioka NS. Pulsed holmium laser ablation of cardiac valves. Lasers Surg Med 1989;9:458-64.

10. Hoskins DH, et al. Subconjunctival THC:YAG laser limbal sclerostomy $a b$ externo in the rabbit. Ophthalmic Surg 1990;2:589-92.

11. Hoskins DH, et al. Subconjunctival THC:YAG laser sclerostomy. Ophthalmology 1991;98:1394-400. 